\title{
Acoustic properties of porous concrete made from arlite and vermiculite lightweight aggregates
}

\author{
J. Carbajo ${ }^{\mathrm{a}} \bowtie$, T.V. Esquerdo-Lloret ${ }^{\mathrm{b}}$, J. Ramis $^{\mathrm{a}}$, A.V. Nadal-Gisbert ${ }^{\mathrm{c}}$, F.D. Denia ${ }^{\mathrm{d}}$
}

a. Department of Physics, Systems Engineering and Signal Theory, University of Alicante (Alicante, Spain)

b. Instituto de Diseño para la Fabricación y Producción Automatizada, Universitat Politècnica de Valencia (Valencia, Spain) c. Instituto de Tecnología de Materiales, Universitat Politècnica de Valencia (Valencia, Spain)

d. Centro de Investigación en Ingeniería Mecánica, Universitat Politècnica de Valencia (Valencia, Spain)

\jesus.carbajo@ua.es

Received 9 February 2015

Accepted 11 May 2015

Available on line 12 N ovember 2015

\begin{abstract}
The use of sustainable materials is becoming a common practice for noise abatement in building and civil engineering industries. In this context, many applications have been found for porous concrete made from lightweight aggregates. This work investigates the acoustic properties of porous concrete made from arlite and vermiculite lightweight aggregates. These natural resources can still be regarded as sustainable since they can be recycled and do not generate environmentally hazardous waste. The experimental basis used consists of different type specimens whose acoustic performance is assessed in an impedance tube. Additionally, a simple theoretical model for granular porous media, based on parameters measurable with basic experimental procedures, is adopted to predict the acoustic properties of the prepared mixes. The theoretical predictions compare well with the absorption measurements. Preliminary results show the good absorption capability of these materials, making them a promising alternative to traditional porous concrete solutions.
\end{abstract}

KEYWORDS: Acoustic impedance; Absorption coefficient; Porous concrete; Lightweight aggregates

Citation/Citar como: Carbajo, J.; Esquerdo-Lloret, T.V.; Ramis, J.; Nadal-Gisbert, A.V.; Denia, F.D. (2015) Acoustic properties of porous concrete made from arlite and vermiculite lightweight aggregates. Mater. Construcc. 65 [320], e072 http://dx.doi.org/10.3989/mc.2015.01115.

RESUMEN: Propiedades acústicas del hormigón poroso a base de áridos ligeros de arlita y vermiculita. El uso de materiales sostenibles se está convirtiendo en una práctica común para la reducción de ruido en las industrias de la edificación e ingeniería civil. Este trabajo investiga las propiedades acústicas de hormigón poroso fabricado a partir de áridos ligeros de arlita y vermiculita. Estos recursos naturales todavía pueden considerarse sostenibles ya que pueden ser reciclados y no generan residuos peligrosos para el medio ambiente. La base experimental utilizada se compone de especímenes de diferente tipo cuyas prestaciones acústicas se evalúan en un tubo de impedancia. Adicionalmente, se ha adoptado un modelo teórico simple para medios porosos granulares, basado en parámetros medibles con procedimientos experimentales básicos, con objeto de predecir las propiedades acústicas de las mezclas preparadas. Las predicciones teóricas muestran una buena concordancia con las medidas de absorción. Los resultados preliminares demuestran la buena capacidad absorbente de estos materiales, haciendo de ellos una alternativa prometedora a las soluciones de hormigón poroso tradicionales.

PALABRAS CLAVE: Impedancia acústica; Coeficiente de absorción; Hormigón poroso; Agregados ligeros

Copyright: (C) 2015 CSIC. This is an open-access article distributed under the terms of the Creative Commons Attribution-Non Commercial (by-nc) Spain 3.0 License. 


\section{INTRODUCTION}

Porous concrete manufactured from lightweight aggregates is each passing day more commonly used for passive noise reduction in the building industry $(1,2)$. Concrete materials, unlike ordinary foams and fibrous absorbers, meet potential properties when used for structural purposes (durability, structural strength, stiffness, etc.) along with a good acoustic performance if properly designed. These consolidated granular materials are also widely used in numerous outdoor noise control applications such as noise barriers $(3,4)$ and in ground surfaces $(5-9)$. In this context, the need to reduce $\mathrm{CO}_{2}$ emissions while limiting traffic noise $(10,11)$ has prompted the civil engineering industry to focus efforts on development of new environmentally friendly granular materials while providing similar sound absorbing characteristics.

Some research has been devoted to study sustainable concrete-based materials, which are usually made from natural or recycled materials. The former, which can be made from vegetable particles, are of great interest inasmuch as they are renewable (12) and often present good sound absorption capabilities (13). Other materials, also called "green materials", come from recycling processes; some of them use residues coming from construction and demolition wastes $(14,15)$, crumb rubber $(16)$ or plastic waste from recycling of electric wires (17). Besides, these new kinds of materials are expected to satisfy thermal, acoustical and increasingly structural demands. A review of sustainable materials for acoustic applications, either natural or made from recycled materials, can be found in (18). Among these, expanded ceramic materials obtained by exfoliation, as in the case of arlite and vermiculite, can still be regarded as sustainable (19) since they can be recycled and do not generate environmentally hazardous waste.

The expanded materials consist of very light dry clay and are obtained from open-pit mining. The virgin rock crushed is placed in an oven at $1200^{\circ} \mathrm{C}$ to generate thermal shock. Combustion gases generate clay expansion, thus increasing arlite and vermiculite particles 5 and 15 times the original size, respectively. The grains of arlite acquire a dark grey colour and a variable size between 2 and $20 \mathrm{~mm}$, while for vermiculite a yellowish layered structure is generated and particles vary between 0.1 and $15 \mathrm{~mm}$. They are marketed in bags of 50 to 100 liters or bulk. Furthermore, not only do they offer a fair durability, but also a low manufacturing cost and good thermal insulation (20). Concrete produced from this type of clays and derivatives presents low density values appropriate for lightweight applications (21-23). The material here considered can be crushed and reused in the preparation of new lightened concrete. Arlite and vermiculite can be used as substitutes for other arids usually employed, e.g., sand and gravel, and also present interesting properties such as nontoxicity and insolubility in water and other organic solvents. They are also harmless, odorless, inert and sterile. In addition, they exhibit stability and insensitivity to atmospheric agents, these properties being kept over time. Raw materials are a natural aggregate, being the use of non-renewable energy in the manufacturing process the main source of environmental pollution. Concerning their use with acoustical purposes, profit from their microporosity looks promising and makes them become an interesting alternative to typically used solutions. Consequently, an experimental and theoretical characterization process is required so as to evaluate their acoustical behaviour. Thereby, the use of predictive impedance models to analize granular porous media is of great interest and may help on the choice of an optimal mix composition providing the maximum average absorption within a prescribed frequency band.

Numerous works have been dedicated to derive formulations of the acoustic impedance of granular porous media (24-27). Most of them assume the material to be composed of stacked discrete elements and include empirical shape factors whose values are frequently fitted to experimental data (28). Early works (29) lead to the assertion that the acoustic properties of consolidated materials, as in the case of porous concrete, are largely influenced by the consolidation process. For these cases, a still simple and practical theoretical alternative was proposed by Horoshenkov and Swift (30), who successfully tested the method on a representative selection of consolidated and non-consolidated porous granular materials. This model was based on four measurable non-acoustic parameters (porosity, tortuosity, flow resistivity and standard deviation of the pore size) assuming a given pore geometry and a pore size distribution close to log-normal, which is often found in granular materials. The prediction method was subsequently shown to be in good agreement with the experimental data for other consolidated granular mixes of concrete using aluminous aggregate (31) and expanded clay granulates (32). This leads to the choice of this model for the study of porous concrete made from lightweight materials as those of the aforementioned type.

The present work aims to explore the effect of arlite and vermiculite lightweight aggregates of different sizes and types on the acoustic performance of porous concrete. For this purpose, five sets of consolidated granular mixes are prepared and therefrom test specimens are manufactured. The normalized surface impedance and sound absorption coefficient under normal incidence of these samples are determined by means of an impedance tube. The experimental results are compared to the predictions of the Horoshenkov and Swift model (30), which uses as input the measured data for porosity, 
tortuosity, flow resistivity and standard deviation of the pore size. The theoretical model shows a reasonable good agreement with the measurements and can thus be used in different areas of construction engineering to acoustically design concrete made from lightweight arlite and vermiculite aggregates.

The structure of the paper is as follows. Section 2 introduces the theoretical background to study the acoustic properties of granular porous media and reviews the well-established Horoshenkov and Swift model. In section 3 , the samples preparation process is explained in detail and the experimental setup used to determine the input parameters of the model and to validate it is briefly described. In addition, an optimization process is presented to derive these parameters when some measurement difficulties arise. In section 4 , impedance tube measurement results are analysed and compared to those obtained in the predictions for some of the manufactured mixes. A discussion on the derived physical parameters and the applicability of the theoretical model are presented together. Finally, section 5 describes the main conclusions of this work.

\section{THEORETICAL BACKGROUND}

\subsection{Acoustic modeling of granular porous media}

Sound propagation in granular porous media is difficult to study on a microscopic scale because of the complex geometry of the frame. Instead, a macroscopic formulation under rigid frame approximation is commonly employed. As the frame is assumed to be motionless, a simplified equivalent fluid approach can be used to derive frequencydependent expressions of its relevant acoustic properties, namely characteristic impedance, $Z(\omega)$, and complex wave number, $k(\omega)$ :

$$
\begin{aligned}
& Z(\omega)=\sqrt{\rho(\omega) / C(\omega),} \\
& k(\omega)=\omega \sqrt{\rho(\omega) C(\omega)},
\end{aligned}
$$

where $\omega$ is the angular frequency, $\rho(\omega)$ is the equivalent fluid density and $C(\omega)$ is the compressibility of the fluid. These quantities account for the viscous friction and thermal loss mechanisms at the pore walls, and are linked to the size of the pores and the proportion of open pores through $\rho(\omega)$ and $C(\omega)$.

The surface impedance $Z_{s}$ and sound absorption coefficient $\alpha$ of a hard-backed granular layer of thickness $h$ for the case of normal incidence are calculated using the following expressions:

$$
\begin{gathered}
Z_{S}=Z \operatorname{coth}(-j k h), \\
\alpha=1-\left|\frac{Z_{S}-\rho_{0} c_{0}}{Z_{S}+\rho_{0} c_{0}}\right|^{2},
\end{gathered}
$$

where $\rho_{0}$ and $c_{0}$ are the density and the sound propagation velocity in air, respectively. The surface impedance is also usually expressed normalized to $\rho_{0} c_{0}$.

Although basic equations [1] to [4] are generic to study the acoustic properties of porous media, they constitute the fundamentals for most of the existing theoretical approaches and will serve for the model adopted here.

\subsection{Horoshenkov and Swift model}

Horoshenkov and Swift (30) derived equations of the previous properties for rigid frame granular media with a log-normal pore size distribution. These expressions can be written in the following form $[5,6]$ :

$$
\begin{aligned}
& \rho(\omega)=\frac{\alpha_{\infty}}{\phi}\left(\rho_{0}-\frac{\phi R}{j \omega \alpha_{\infty}} \tilde{F}(\omega)\right), \\
& C(\omega)=\frac{\phi}{\gamma P_{0}}\left(\gamma-\frac{\rho_{0} \alpha_{\infty}(\gamma-1)}{\phi \rho\left(N_{p r} \omega\right)}\right),
\end{aligned}
$$

where $\alpha_{\infty}$ is the tortuosity, $\phi$ is the porosity, $R$ is the flow resistivity, $\gamma$ is the ratio of specific heats, $P_{0}$ is the atmospheric pressure and $N_{p r}$ is the Prandtl number. $\tilde{F}$ is the viscosity correction function, which can be presented in the form of a Padé approximation as [7]:

$$
\tilde{F}(\omega) \cong \frac{1+a_{1} \varepsilon+a_{2} \varepsilon^{2}}{1+b_{1} \varepsilon},
$$

with $a_{1}=\theta_{1} / \theta_{2}, a_{2}=\theta_{1}$ and $b_{1}=a_{1}$, being $\theta_{1}=4 e^{4 \xi} / 3-1$ and $\theta_{2}=e^{3 \xi / 2} / \sqrt{2}$ for the circular pore geometry assumption, where $\xi=(\sigma \ln 2)^{2}$ and $\sigma$ is the standard deviation in the log-normally distributed pore size, and $\varepsilon=\sqrt{-j \omega \rho_{0} \alpha_{\infty} /(R \phi)}$ is a dimensionless parameter.

The presented model is used in this work to predict the acoustic properties of various consolidated granular samples made from arlite and vermiculite aggregates using a cementitious binder. The corresponding material preparation is described next.

\section{METHODOLOGY}

\subsection{Sample preparation}

The acoustical and non-acoustical properties of five sets of consolidated granular mixes made from lightweight aggregates using cementitious binder are to be investigated experimentally. Each set comprises six samples having the same dimensions and the five sets consist of small and large grain arlite, small and large grain vermiculite type 2 and large grain 
vermiculite type 3 . This number of samples was considered representative enough for comparison between sets. Figure 1 shows the morphology of the three types of lightweight aggregates used in this study.

First, since the starting arlite and vermiculite grains have various sizes, a tapping sieve analysis was carried out to assess the gradation of the aggregates. It was performed using the digital mechanical shaker CISA model RP09 with perforated plate sieves following the UNE-EN 933-2 standard (33). The test results showed that the arlite grains range mainly from 2 to $8 \mathrm{~mm}$ in diameter, whereas the vermiculite type 2 grains range from 0.25 to $2 \mathrm{~mm}$ and the vermiculite type 3 from 0.5 to $4 \mathrm{~mm}$. As mentioned previously, two different particle size ranges were extracted for the arlite and vermiculite type 2 sets.

In a following step, and in order to produce a firm consolidated porous structure from the loose granular material, a kneading process was undertaken by means of a cementitious binder. In this work, the samples were made by dissolving high strength white Portland cement BL I 52.5 R in water until having a homogeneous mixture and then adding the aggregates while using a mechanical autoclave type orbital BOMANN model CB 332 at 69 r.p.m (level 3) for about 10-15 minutes following the UNE EN 196-1 standard (34). No plasticizers or extra admixtures were added. The resulting mixes were arranged in $72 \mathrm{~mm}$ diameter and $50 \mathrm{~mm}$ thick moulds for 48 hours before being extracted for the complete curing of the samples for a period 30 days at $23{ }^{\circ} \mathrm{C}$ and $34 \%$ relative humidity at ambient conditions and weighing thereof. It should be noted that this consolidation process may have a substantial influence on the acoustic properties of the samples, i.e., the binder quantity used has a critical effect on the size and distribution of the pores in the final mix. In our case, preliminary trial and error tests were necessary to choose adequate binder quantities to ensure enough cohesion for subsequent handling and sufficient proportion of open pores. This work phase led to the use of a lower aggregatebinder ratio for the case of large grain vermiculite type 2, obtaining a morphology similar to that of the consolidated mix of large grain arlite but much (a)

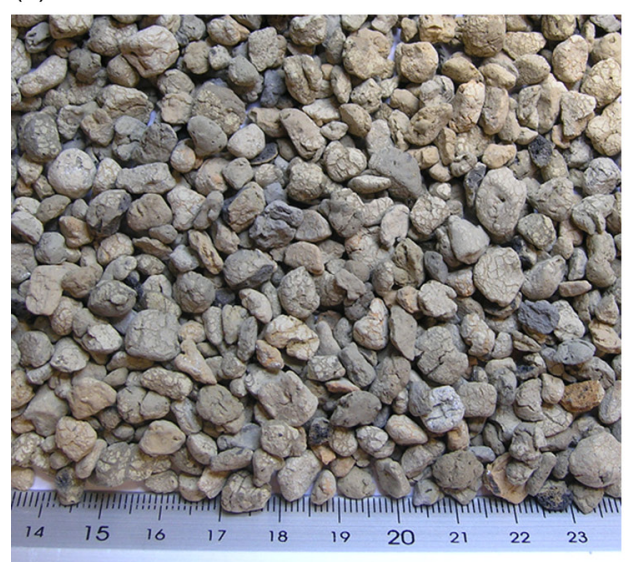

(b)

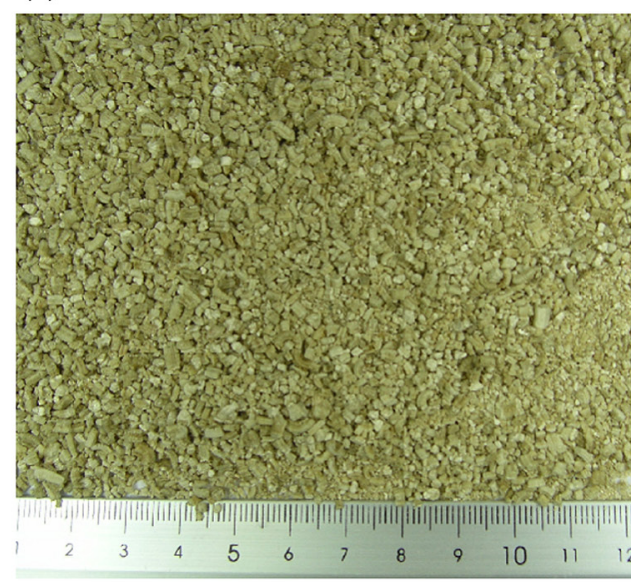

(c)

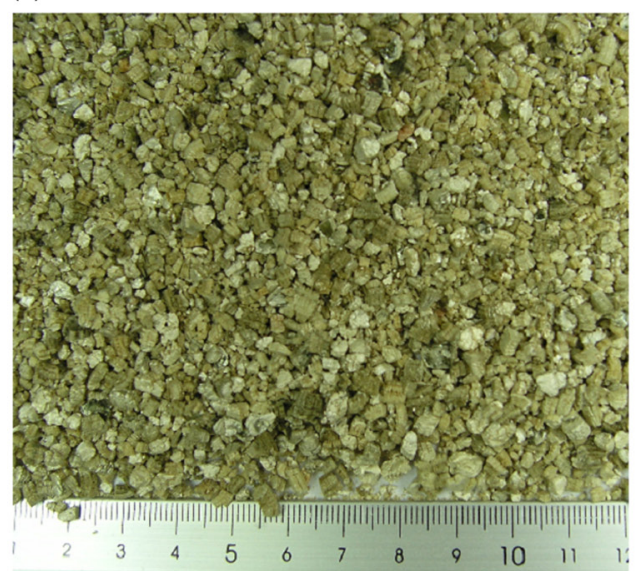

FIGURE 1. Morphology of the three types of lightweight aggregates used: (a) arlite; (b) vermiculite type 2 and (c) vermiculite type 3. 
TABLE 1. Granular mixes preparation data

\begin{tabular}{lccc}
\hline Granular mix & $\begin{array}{c}\text { Grain size } \\
(\mathbf{m m})\end{array}$ & $\begin{array}{c}\mathbf{A} / \mathbf{C} / \mathbf{W}^{*} \\
(\mathbf{\%})\end{array}$ & $\begin{array}{c}\text { Dry density } \\
\left(\mathbf{k g} / \mathbf{m}^{3}\right)\end{array}$ \\
\hline Arlite (A) & $\leq 4$ & $50 / 33 / 17$ & 650 \\
& $>4$ & $50 / 33 / 17$ & 700 \\
Vermiculite type 2 (V2) & $\leq 1$ & $11 / 55 / 34$ & 640 \\
& $>1$ & $12 / 49 / 39$ & 560 \\
Vermiculite type 3 (V3) & $0.5-4$ & $11 / 56 / 33$ & 690
\end{tabular}

* A/C/W indicates the Aggregate, Cement and Water proportions of each mix, respectively.

less dense. Special attention was paid to the fact that the vermiculite offers a higher water absorbing capacity when compared to arlite. Furthermore, each grain of the final consolidated mix may contain several particles of aggregate.

The granular mixes preparation data for the five sets is given in Table 1. Hereinafter, each mix will be denoted using the following abbreviations: A (arlite); V2 (vermiculite type 2) and V3 (vermiculite type 3), distinguishing two grain sizes (small and large) for the two first mix types. The description of the characteristics for the tested samples is provided in Table 2. Photographs of three consolidated specimens corresponding to the sets of large grain A, large grain V2 and V3 are shown in Figure 2. It is worth recalling the relatively similar morphology for the two first cases in spite of having a significant density reduction in the case of large grain V2. A more detailed view of these samples is also given in the images captured using a photo camera attached to a magnifying glass system and trimming the resulting image to a circular diameter of $22 \mathrm{~mm}$ using an image editor. In these images, the previously mentioned bonding difficulties for the case of vermiculite stand out.

\subsection{Experimental setup}

The theoretical model described in Section 2.2 is based on four measurable physical properties: porosity, tortuosity, flow resistivity and standard deviation of the pore size. The corresponding values can be determined using basic experimental procedures.
The porosity measures the empty space in a material and is calculated from $\phi=V_{f} / V_{t}$, where $V_{f}$ is the volume of fluid-space and $V_{t}$ the total volume of the material sample. In the case of consolidated porous concrete, the dry samples volume is measured before immersing them in water for 24 hours to be moisturized. Thereafter, the samples are placed in a vessel and water is poured on it until pore structure is saturated. Then, the filling liquid is removed to a flask and the volume of evicted water measured. This procedure has been shown to provide similar results to those used in other previously referred works $(4,6,32)$. Consolidated materials have more complex pore networks that include closed pores (or non-connected cavities), nevertheless they may be neglected as considered inaccessible to airflow.

The tortuosity is a property that gives a measure of the geometric complexity of a porous material as the ratio of the real distance between both extremes and that of a straight line. That is to say, it indicates the ease of an acoustic wave to propagate inside the material. Given the inherent pseudodestructive features in using any of the commonly adopted chemical methods (35) that require the use of an electrolyte, an inverse methodology described later was used instead to determine this property.

The flow resistivity measures the resistance that a porous structure offers to the air flow and hence gives an idea of the energy loss occurring inside the material. Even though standardized laboratory procedures to measure this parameter exist (36), a simpler alternative acoustic method developed by Ingard and Dear (37) was used. This method is based on acoustic measurements in an impedance tube with a pair of microphones, here conducted in an improved way using a digital analyser that generates a random signal. The resistivity itself is thereupon obtained as the ordinate value from a linear fit of the flow resistivity values at audible frequencies where the sample-rigid termination distance is an odd number of quarter wavelengths, being the thickness of the sample under test necessarily much smaller than the wavelength involved. This method can be regarded as indirect inasmuch as it estimates the zero frequency flow resistivity from higher frequency values measured.

TABLE 2. Characteristics of the prepared samples

\begin{tabular}{lccc}
\hline Granular mix & & $\begin{array}{c}\text { Effective } \\
\text { thickness (mm), } \boldsymbol{h}\end{array}$ & $\begin{array}{c}\text { Dry } \\
\text { weight (g) }\end{array}$ \\
\hline Arlite (A) & $\leq 4 \mathrm{~mm}$ & $51.0(0.5)$ & $135(8)$ \\
& $>4 \mathrm{~mm}$ & $50.7(1.0)$ & $143(3)$ \\
Vermiculite type 2(V2) & $\leq 1 \mathrm{~mm}$ & $50.6(1.0)$ & $135(7)$ \\
& $>1 \mathrm{~mm}$ & $50.5(1.5)$ & $115(6)$ \\
Vermiculite type 3(V3) & $0.5-4 \mathrm{~mm}$ & $50.9(0.4)$ & $144(7)$ \\
\hline
\end{tabular}

The values in parenthesis indicate the maximum deviation from the averaged value. 
(a)

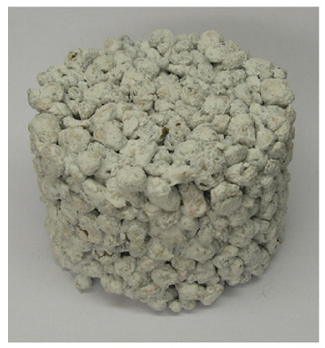

(b)

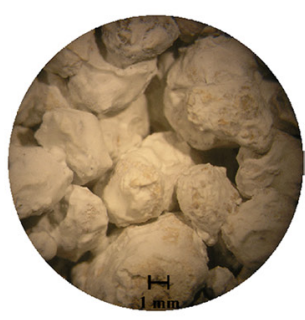

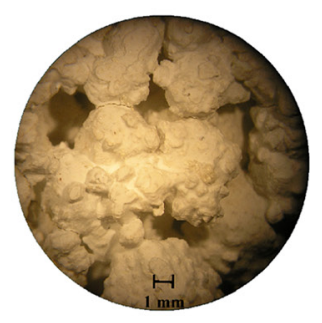

(c)
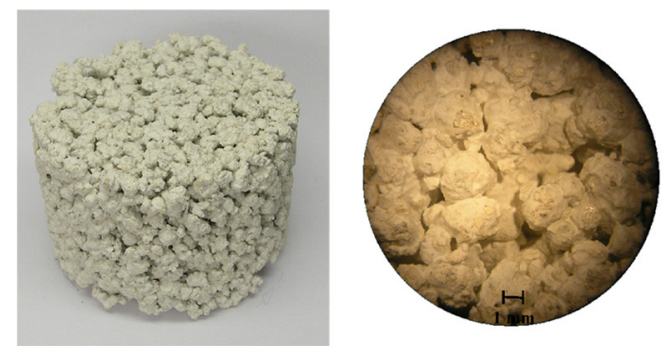

Figure 2. (Left) Photographs and (Right) trimmed zoomed image for test specimens of porous concrete made from: (a) large grain A; (b) large grain V2 and (c) V3.

The mean pore size and its standard deviation are other important parameters when studying acoustic porous materials, the latter being an input of the model used in this work. This parameter measures the dispersion from the average pore size and gives an idea of the distribution of pores. The standard deviation can be determined through theoretically fitting the cumulative pore size distribution measured using the water suction method (38) to the integration of a log-normal statistical distribution with the probability density function [8]:

$$
P D F(\varphi)=\frac{1}{\sigma \sqrt{2 \pi}} e^{-\left((\varphi-\langle\varphi\rangle)^{2} / 2 \sigma^{2}\right)},
$$

with $s$ being the pore size in standard units determined from the experiment, $\varphi$ is defined as $\varphi=-\log _{2} S$ and the median value is calculated as $\langle\varphi\rangle=-\log _{2}\langle s\rangle$.

In a second step, and so as to validate the application of the theoretical model to this type of mixes, the sound absorption coefficient under normal incidence of the prepared samples was measured following the standardized impedance tube method (39) in the frequency range 200-2200 Hz. Both impedance tube methods, that of Ingard and Dear (37) and that just mentioned, were performed arranging the samples so that the incoming acoustic wave impinges on the rougher surface of the sample. This setup consists of two custom-made tubes: one for the loudspeaker section and the other for the rigid termination, coupled by a sample holder as indicated in the schematic of Figure 3. The specimen is placed in this sample holder and this in turn attached to the tubes using adjustable screws on threaded bars. An additional rigid piece is placed behind the sample for the absorption measurements whereas it is removed for the flow resistivity experiments. In this manner, both methods can be performed in a versatile way using a unique experimental rig. The tubes have circular cross-section with a thickness of $6 \mathrm{~mm}$ and a cut-off frequency around $2500 \mathrm{~Hz}$. All the elements are made from stainless steel. A random excitation is provided to the loudspeaker from the analyser (OR34 Compact Analyser) and the corresponding pressure transfer functions are measured subsequently using two $1 / 2$ in. pressure microphones (B\&K Type 4188) mounted flush with the inner surface of the tubes at their respective locations (1, 2: absorption; 3, 4: flow resistivity). Acquisition data was post-processed in Matlab. Since the acoustic analysis of the present study is based upon linear models, the incident sound pressure level in the impedance tube has been kept below $90 \mathrm{~dB}$. The frequency range of analysis

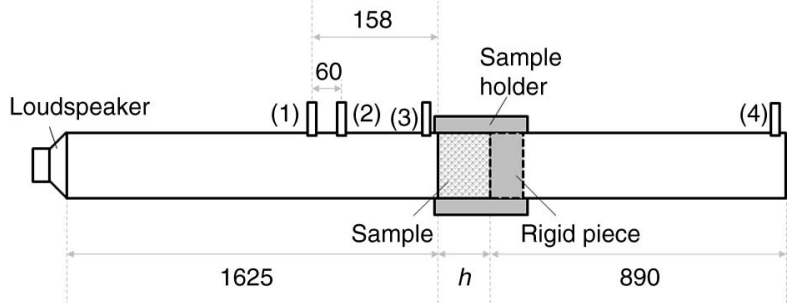

FIGURE 3. Schematic of the impedance tube used for both absorption and flow resistivity measurements (dimensions are in $\mathrm{mm}) . h$ is the sample thickness and ( $\mathrm{i}=1 \ldots 4)$ are the microphone positions. 
was chosen to ensure plane wave propagation and avoid excitations of higher order modes. The resultant sound absorption coefficient and flow resistivity of the absorbent materials can thus be obtained.

\subsection{Inverse numerical method}

To avoid some of the limitations discussed above, it is common to use some optimization method to determine indirectly the input parameters that let the acoustic model obtain the best fit to the impedance tube measurements $(40,41)$. This procedure is also recurrently used when any of the previous physical parameters are difficult to measure or cannot be properly determined, as it was in the current investigation for the tortuosity. The Nelder-Mead direct search optimization method (42) is a technique that minimizes an objective function of one or several variables from an initial estimate and serial iterations until the specified tolerance is achieved, though it can sometimes present discontinuities or no convergence problems. Hence, for these cases where the required adjustment is within the experimental tolerance values, this inverse numerical method is proven to be a useful tool to accurately estimate the physical properties of granular mixes in a simple manner.

For this purpose, the following objective function is defined [9]:

$$
O F\left(\alpha_{\infty}\right)=\sum_{i=1}^{N}\left|\alpha\left(f_{i}\right)-\hat{\alpha}\left(f_{i}, \alpha_{\infty}\right)\right|,
$$

where $\alpha\left(f_{i}\right)$ and $\hat{\alpha}\left(f_{i}\right)$ correspond to the measured and the estimated sound absorption coefficient under normal incidence for each frequency of interest $f_{i}$, respectively. Hereby, the design variable parameter (tortuosity $\alpha_{\infty}$ in our case) that best fits the experimental data to the theoretical model is obtained.

\section{RESULTS AND DISCUSSION}

\subsection{Physical parameters}

Table 3 summarizes the physical properties of the five granular mixes tested. These are obtained by averaging the values measured in each of the six samples of their respective sets. The prediction of the acoustic properties was carried out using these values as input data in the theoretical model.

Porosity measurements for the prepared mixes indicate similar values of around 39\% for this material property. As stated above, vermiculite high water absorbing capacity can result in very misleading values of porosity if not carefully measured, but are still acceptable for practical purposes. Tortuosity values indicate that for the same mix type the grain size has a slight influence on them. Nevertheless, it should be recalled that this property has been obtained through an inverse method and therefore it is worth noting that further experimental work is required to confirm this. Flow resistivity values show to be inversely proportional to the grain particle size of the samples, as the sound propagation damping increases with the reduced grain size. This assertion is not true for excessively high values of flow resistivity, as it would involve too high characteristic impedance values and therefore worsen air-granular mix impedance coupling, yielding less sound absorption. With this in mind, lower grain sizes attain higher flow resistivity values for the cases examined.

Figure 4 displays the average cumulative pore size distribution obtained experimentally and the theoretical fitted curve using equation [8] for each granular mix set. The average standard deviation fitted values are in the range $0.17-0.24$. The resulting data verifies that the pore size distribution is lognormal for these granular materials. The vermiculite type 3 mixes exhibit smaller pores and highest value of standard deviation of pore size, somewhat due to the relatively broadest grain size range.

\subsection{Acoustic properties}

Figure 5 shows the average measured sound absorption coefficient for the sets of granular mixes tested. The acoustic behaviour of these materials is governed by their dimensions, the porosity, the pore shape and size along with their distribution. Indeed, the dimensions and the porosity are of the same order for all the samples so that maximum absorption frequency range $1000-1400 \mathrm{~Hz}$ is alike, being the differences of the sound absorption coefficient

TABLE 3. Average measured physical properties of the granular mixes used in the theoretical model

\begin{tabular}{lccccc}
\hline Granular mix & Porosity, $\phi$ & Tortuosity, $\boldsymbol{\alpha}_{\infty}^{*}$ & $\begin{array}{c}\text { Flow resistivity } \\
\left(\mathbf{P a} \cdot \mathbf{s} \cdot \mathbf{m}^{-2}\right), \boldsymbol{R}\end{array}$ & $\begin{array}{c}\text { Standard } \\
\text { deviation, } \boldsymbol{\sigma}\end{array}$ \\
\hline Arlite (A) & $\leq 4 \mathrm{~mm}$ & 0.39 & 1.82 & 2176 & 0.21 \\
& $>4 \mathrm{~mm}$ & 0.38 & 1.87 & 1839 & 0.16 \\
Vermiculite type 2 (V2) & $\leq 1 \mathrm{~mm}$ & 0.39 & 1.70 & 2230 & 0.17 \\
& $>1 \mathrm{~mm}$ & 0.37 & 1.73 & 1424 & 0.17 \\
Vermiculite type 3 (V3) & $0.5-4 \mathrm{~mm}$ & 0.40 & 1.70 & 1720 & 0.24 \\
\hline
\end{tabular}

* Tortuosity values were obtained with the inverse numerical method described in Section 3.3. 


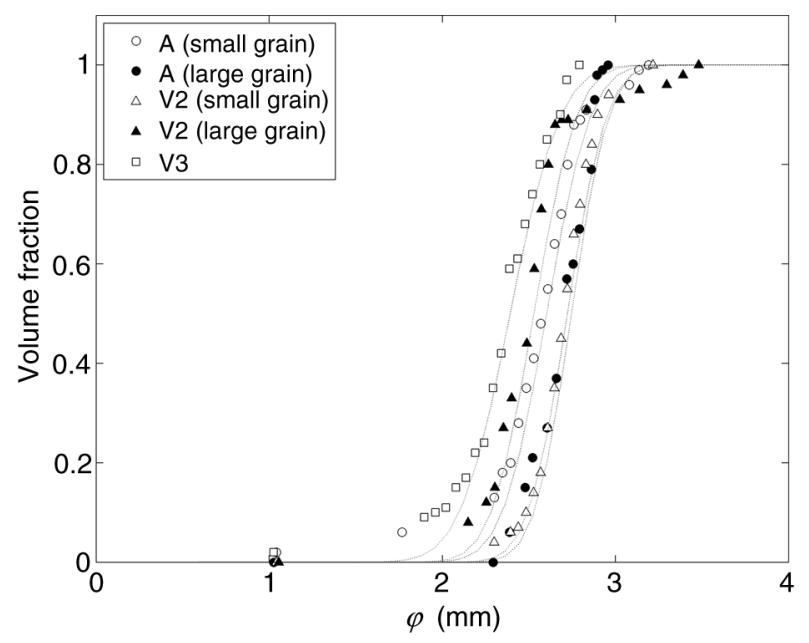

FIgURE 4. Cumulative pore size distribution for the granular mix sets analyzed. The markers denote experimental data and the dotted lines the theoretical fit.

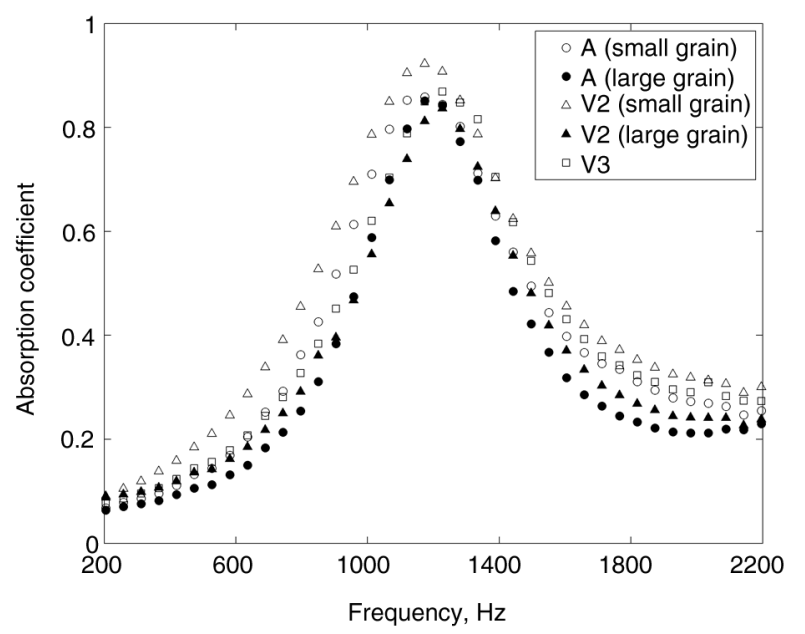

FIGURE 5. Sound absorption coefficient for the different sets of granular mixes.

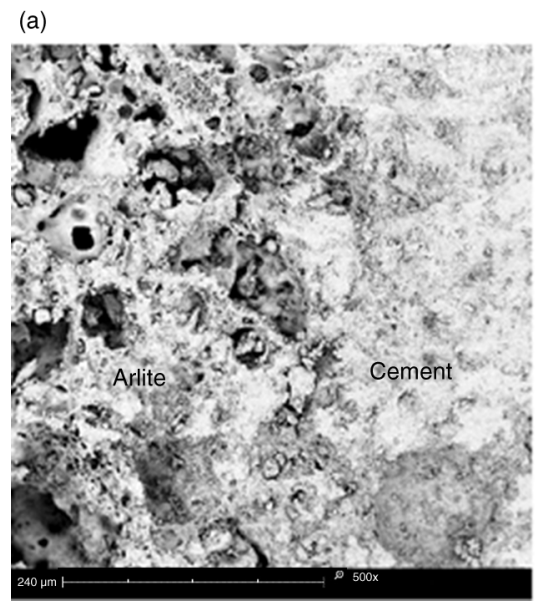

amplitude particularly due to the two latter parameters. This bandwidth depends on the design parameters of the granular mix (grain size, binder, A/C/W proportions,...), whose modification could even lead to different absorption properties. The impedance tube experiments suggest that the smaller grain mixes show higher sound absorption and a broader frequency range than those made from larger grains. This is partly due to their relatively higher flow resistivity, whilst the enhanced sound attenuation in the high frequency range may be attributed to the major importance of viscothermal loss mechanisms through the narrower porous structure. Moreover, the peak frequency shift towards lower frequencies as the grain size is reduced might be also linked to a higher value of flow resistivity, which is associated with the higher attenuation of the acoustic waves in the granular material. Notice that for the analysed cases a slight porosity reduction results in a poorer acoustic performance, somehow due to the binder effects on the grain disposition and final pore structure.

The SEM images on a cut flat surface of residual grains of the large grain $\mathrm{A}$ and the $\mathrm{V} 3$ mixes illustrate some differences between arlite and vermiculite aggregates (Figure 6). While arlite evidences the expansion process in the form of an internal macroporous product, vermiculite provides a flat and well defined lamellar structure surrounded by cement on its boundaries. In both cases, a fairly good adhesion with a continuous interface aggregate-cement is observed.

Figure 7 depicts the average real and imaginary parts of the normalized surface impedance of the large grain A mix, the small grain V2 mix and the V3 mix. For the large grain mix, the real and imaginary parts of the surface impedance increase in amplitude at low frequencies and above $1800 \mathrm{~Hz}$, while for the other mixes this occurs at lower values. As a consequence, the width of the frequency range

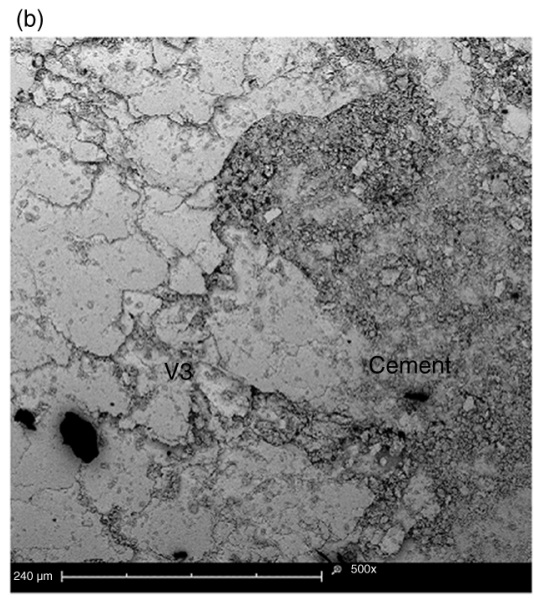

Figure 6. SEM image for test samples of porous concrete made from: (a) large grain A and (b) V3. 


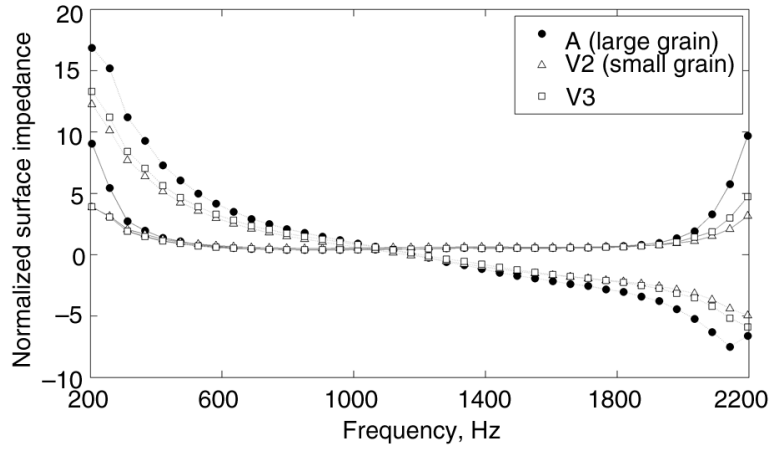

FIGURE 7. Normalized surface resistance (continuous line) and reactance (dotted line) for the large grain A, small grain V2 and V3 mixes.

at which sound absorption is effective becomes reduced for the large grain mix. This raise in the surface impedance also yields lower absorption values for this mix type and explains the worst impedance match in the air-granular mix interaction region. On the other hand, the frequency associated with the zero value of the surface reactance (imaginary part of the surface impedance) is observed to be nearly unchanged from this mix set to the others. A frequency shift of the sound absorption peak towards lower frequencies is more pronounced for the small grain with respect to the large grain of the same aggregate type, as it was prior appreciated in Figure 5.

In addition, the experimental results for the sound absorption coefficient have been compared to those predicted by the theoretical model using the measured physical parameters for some of the manufactured mixes. In Figure 8 a good agreement between the predictions and the impedance tube tests is verified throughout the frequency range $500-1800 \mathrm{~Hz}$, showing some discrepancies at frequencies above $1800 \mathrm{~Hz}$ and in the low frequency range. A closest match is found for the case of large grain A whereas the theoretical model is less accurate in the case of large grain V2 and V3, likely due to the lower reliability of the experiments involving water in this type of samples and/or other measurement errors. These differences may be a result of both front surface roughness and no flow occurring through deadend pores (pores connected to the exterior at only one end of the sample). Furthermore, the circular pore shape assumption may not be as close to manufactured samples. Alternatively, other pore geometries could be used for the predictions, though this is usually unknown or not easy to define.

\section{CONCLUSIONS}

This work presents and analyses the acoustic properties of porous concrete made from lightweight arlite and vermiculite aggregates of different sizes and types. For this purpose, several mixes were prepared and impedance tube measurements were performed on manufactured specimens. The results indicate that these consolidated materials yield a relative high sound absorption and can thus become a sustainable alternative to other commonly used solutions in practical applications. Additionally, predictions are obtained for the sound absorption coefficient based upon a general theoretical model whose input parameters (porosity, tortuosity, flow resistivity and standard deviation of the pore size) have been easily determined through basic experimental procedures. In general, measured and estimated values showed a relative good agreement and confirm that the model can be successfully used for the design of porous concrete made from arlite and vermiculite aggregates.

Summarizing, these materials (arlite and vermiculite) have adequate structural strength for manufacturing and manipulation purposes. The final concrete product is attachable to existing elements such as plasterboard, plaster and false ceilings, and can be used as visible or hidden construction solutions. A number of different characteristics can be obtained, including texture, roughness, arbitrary shape and thickness. In the case of sound walls, these can be manufactured with special shapes like undulations or projections. In addition, these materials allow aesthetic applications and can include perforations.
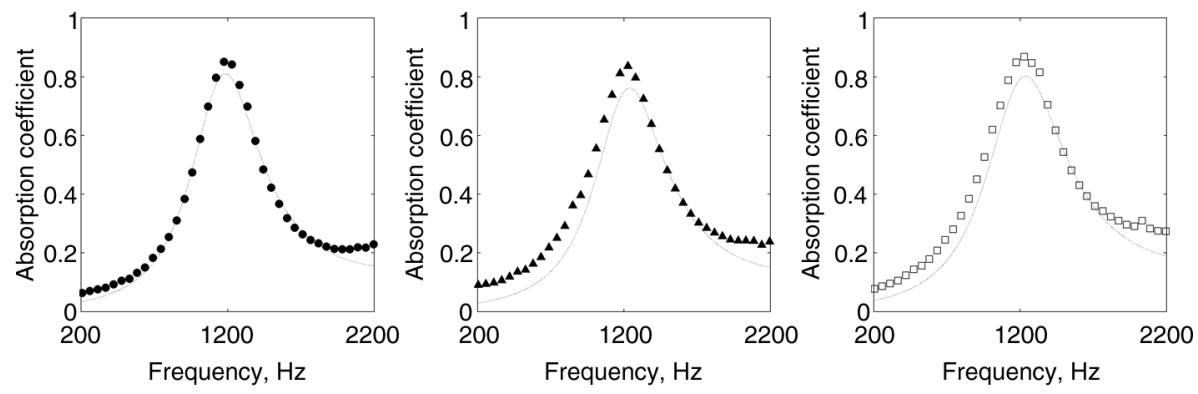

FIGURE 8. Measurement (markers) and prediction (dotted line) results of sound absorption coefficient for: (left) large grain A, (center) large grain V2 and (right) V3. 
As indicated in the Introduction, interesting properties regarding sustainability are obtained, as arlite and vermiculite are ecological products. These include recyclability as well as nontoxicity, insolubility in water and other organic solvents, and also chemical stability over time. In addition, they are relatively cheap, thus providing relevant advantages from a commercial point of view. The concrete lightened with these products can be crushed and recycled to prepare new lightweight concrete.

Even though further research is needed to assess the acoustic performance for other mix proportions, preliminary results look promising and encourage work on the development of porous concrete made from these materials for its use in building and civil engineering industries.

\section{ACKNOWLEDGEMENTS}

We would like to thank Philippe Leclaire for helping us with details concerning the water suction method.

\section{REFERENCES}

1. Branco, F.G.; Godinho, L. (2013) On the use of lightweight mortars for the minimization of impact sound transmission. Constr. Build. Mater. 45, 184-191. http://dx.doi.org/10.1016/j. conbuildmat.2013.04.001

2. Tutikian, B.F.; Nunes, M.F.O.; Leal, L.C.; Marquetto, L. (2013) Hormigón ligero con agregado reciclado de EVA para atenuación del ruido de impacto. Mater. Construcc. 63 [310], 309-316. http://dx.doi.org/10.3989/mc.2012.06911.

3. Krezel, Z.A.; McManus, A.M.K. (2000) Recycled aggregate concrete sound barriers for urban freeways. Waste Management Series. 1, 884-892. http://dx.doi.org/10.1016/ S0713-2743(00)80097-5.

4. Kim, H.K.; Lee, H.K. (2010) Influence of cement flow and aggregate type on the mechanical and acoustic characteristics of porous concrete. Appl. Acoust. 71, 607-615. http:// dx.doi.org/10.1016/j.apacoust.2010.02.001

5. Olek, J.; Weiss, W.J.; Neithalath, N. (2004) Concrete mixtures that incorporate inclusion to reduce the sound generated in Portland cement concrete pavements. Final report SQDH 2004-2. The Institute for Safe, Quite and Durable Highways. Purdue University Center for Advanced CementBased Materials Northwestern University.

6. Neithalath, N. (2004) Developement and characterization of acoustically efficient cementitious materials, Ph. D. Tesis, Purdue University.

7. Tiwari, V.; Shukla, A.; Bose, A. (2004) Acoustic properties of cenosphere reinforced cement and asphalt concrete. Appl. Acoust. 65, 263-275. http://dx.doi.org/10.1016/j.apacoust. 2003.09.002

8. Losa, M.; Leandri, P.; Bacci, R. (2008) Mechanical and performance-related properties of asphalt mixes containing expanded clay aggregate. Transp. Res. Record. 23-30. http:// dx.doi.org/10.3141/2051-04.

9. Freitas, E.; Mendonça, C.; Santos, J.A.; Murteira, C.; Ferreira, J.P. (2012) Traffic noise abatement: How different pavements, vehicle speeds and traffic densities affect annoyance levels. Transp. Res. Part D 17, 321-326. http://dx.doi. org/10.1016/j.trd.2012.02.001.

10. EEA: "Noise in Europe 2014". Publications office of the European Union (2014). ISBN 978-92-9213-505-8. http:// dx.doi.org/10.2800/763331.

11. Pacheco-Torgal, F. (2014) Eco-efficient construction and building materials research under the EU Framework Programme Horizon 2020. Constr. Build. Mater. 51, 151-162. http://dx.doi.org/10.1016/j.conbuildmat.2013.10.058.
12. Pacheco-Torgal, F.; Jalali, S. (2011) Cementitious building materials reinforced with vegetable fibres: A review. Constr. Build. Mater. 25 [2], 575-581. http://dx.doi.org/10.1016/j. conbuildmat.2010.07.024.

13. Glé, P.; Gourdon, E.; Arnaud, L. (2012) Modelling of the acoustical properties of hemp particles. Constr. Build. Mater. 37, 801-811. http://dx.doi.org/10.1016/j.conbuildmat.2012. 06.008 .

14. Radonjanin, V.; Malešev, M.; Marinković, S.; Al Malty, A.E.S. (2013) Green recycled aggregate concrete. Constr. Build. Mater. 47, 1503-1511. http://dx.doi.org/10.1016/j. conbuildmat.2013.06.076.

15. Chen, S.H.; Wang, H.Y.; Jhou, J.W. (2013) Investigating the properties of lightweight concrete containing high contents of recycled green building materials. Constr. Build. Mater. 48, 98-103. http://dx doi.org/10.1016/j.conbuildmat 2013.06.040.

16. Holmes, N.; Browne, A.; Montague, C. (2014) Acoustic properties of concrete panels with crumb rubber as a fine aggregate replacement. Constr. Build. Mater. 73, 195-204. http://dx.doi.org/10.1016/j.conbuildmat.2014.09.107.

17. D'Alessandro, F.; Asdrubali, F.; Baldinelli, G. (2014) Multi-parametric characterization of a sustainable lightweight concrete containing polymers derived from electric wires. Constr. Build. Mater. 68, 277-284. http://dx.doi.org/ 10.1016/j.conbuildmat.2014.06.075.

18. Asdrubali, F.; Schiavoni, S.; Horoshenkov, K.V. (2012) A review of sustainable materials for acoustic applications. Building Acoustics. 19 [4], 283-312. http://dx.doi.org/10.1260/ 1351-010X.19.4.283.

19. IMA Europe. Industrial Materials. "Vermiculite", web site: http://www.ima-europe.eu/sites/ima-europe.eu/files/minerals/ Vermiculite_WEB-2011.pdf.

20. Melo, M.O.B.C. Bueno, L ; Coutinho, A.S. Sousa, V; Perazzo, N. (2012) Energy efficiency in building installations using thermal insulating materials in northeast Brazil. Energ. Buildings. 47, 35-43. http://dx.doi.org/10.1016/j.enbuild. 2011.11.021

21. Hossain, K.M.A.; Ahmed, S.; Lachemi, M. (2011) Lightweight concrete incorporating pumice based blended cement and aggregate: Mechanical and durability characteristics. Constr. Build. Mater. 25, 1186-1195. http://dx.doi. org/10.1016/j.conbuildmat.2010.09.036.

22. Schackow, A.; Effting, C.; Folgueras, M.V.; Güths, S.; Mendes, G.A. (2014) Mechanical and thermal properties of lightweight concretes with vermiculite and EPS using airentraining agent. Constr. Build. Mater. 57, 190-197. http:// dx.doi.org/10.1016/j.conbuildmat.2014.02.009.

23. Palomar, I.; Barluenga, G.; Puentes, J. (2015) Lime-cement mortars for coating with improved thermal and acoustic performance. Constr. Build. Mater. 75, 206-314. http:// dx.doi.org/10.1016/j.conbuildmat.2014.11.012.

24. Attenborough, K. (1983) Acoustical characteristics of rigid fibrous absorbents and granular materials. J. Acoust. Soc. Am. 73 [3]. http://dx.doi.org/10.1121/1.389045.

25. Miki, Y. (1990) Acoustical properties of porous materials Generalizations of empirical models. J. Acoust. Soc. Jpn, 11 [1], 25-28. http://dx.doi.org/10.1250/ast.11.25.

26. Stinson, M.R.; Champoux, Y. (1992) Propagation of sound and the assignment of shape factors in model porous materials having simple pore geometries. J. Acoust. Soc. Am. 91 [2], 265-295. http://dx.doi.org/10.1121/1.402530.

27. Allard, J.F. (1992) New empirical equations for sound propagation in rigid frame fibrous materials. J. Acoust. Soc. Am. 91 [6], 3346-3353 http///dx doi.org/10.1121/1.402824.

28. Attenborough, K.; Bashir, I.; Taherzadeh, S. (2011) Outdoor ground impedance models. J. Acoust. Soc. Am. 129 [5], 2806-2819. http://dx.doi.org/10.1121/1.3569740.

29. Swift, M.J.; Bris, P.; Horoshenkov, K.V. (1999) Acoustic absorption in re-cycled rubber Granulate. Appl. Acoust. 57, 203-212. http://dx.doi.org/10.1016/S0003-682X(98)00061-9.

30. Horoshenkov, K.V.; Swift, M.J. (2001) The acoustic properties of granular materials with pore size distribution close to log-normal. J. Acoust. Soc. Am. 110 [5], 2371-2378. http:/l dx.doi.org/10.1121/1.1408312.

31. Horoshenkov, K.V.; Hughes, D.C.; Cwirzen, A. (2003) The sound speed and attenuation in loose and consolidated 
granular formulations of high alumina cements. Appl. Acoust. 64, 197-212. http://dx.doi.org/10.1016/S0003-682X (02)00069-5.

32. Vasina, M.; Hughes, D.D.; Horoshenkov, K.V.; Lapcik Jr, L. (2006) The acoustical properties of consolidated expanded clay granulates. Appl. Acoust. 647, 787-796. http://dx.doi. org/10.1016/j.apacoust.2005.08.003.

33. AENOR: UNE-EN 933-2:1996. Ensayo para determinar las propiedades geometricas de los aridos. Parte 2: Determinación de la granulometría de las partículas. Tamices de ensayo, tamaño nominal de las aberturas, Madrid (1996), ICS 91.100.15-30.

34. AENOR: UNE-EN 196-1:2005. Métodos de ensayo de cementos. Parte 1: Determinación de resistencias mecánicas, Madrid (2005), ICS 91.100.10.

35. Brown, R.J.S. (1980) Connection between formation factor of electrical resistivity and fluid-solid coupling factor in Biot's equation for acoustic waves in fluid-filled porous media. Geophys. 45, 1269-1275. http://dx.doi.org/10.1190/1. 1441123.

36. ISO 9053:1991. Acoustics - Materials for acoustical applications - Determination of airflow resistance, (1991), ICS 91.100 .60 .
37. Ingard, K.U.; Dear, T.A. (1985) Measurement of acoustic flow resistances. J. Sound Vib. 103 [4], 567-572. http:// dx.doi.org/10.1016/S0022-460X(85)80024-9.

38. Leclaire, P.; Swift, M.J.; Horoshenkov, K.V. (1998) Determining the specific area of porous acoustic materials from water extraction data. Appl. Phys. 84 [12], 6886-6890. http://dx.doi.org/10.1063/1.368985.

39. AENOR: UNE-EN ISO 10534-2:2002. Acústica. Determinación del coeficiente de absorcion acustica y de la impedancia acústica en tubos de impedancia. Parte 2: Método de la función de transferencia, Madrid (2002), ICS 17.140.01.

40. Geslain, A.; Groby, J.P.; Dazel, O.; Mahasaranon, S.; Horoshenkov, K.V.; Khan, A. (2012) An application of the Peano series expansion to predict sound propagation in materials with continuous pore stratification. J. Acoust. Soc. Am. 132 [1], 208-215. http://dx.doi.org/10.1121/1.4728188.

41. Ramis, J.; del Rey, R.; Alba, J.; Godinho, L.; Carbajo, J. (2014) A model for acoustic absorbent materials derived from coconut fiber. Mater. Construcc. 64 [313], http://dx.doi. org/10.3989/mc.2014.00513

42. Nelder, J.A.; Mead, R. (1965) A simpex method for function minimization. Comput. J. 7, 308-313. http://dx.doi.org/ 10.1093/comjnl/7.4.308 